\title{
Preparation of high-entropy carbides by different sintering techniques
}

\author{
Johannes Pötschke ${ }^{1, \star}$ (1), Manisha Dahal ${ }^{2}$, Mathias Herrmann ${ }^{1}$, Anne Vornberger ${ }^{1}$, \\ Björn Matthey ${ }^{1}$, and Alexander Michaelis ${ }^{1,2}$ \\ ${ }^{1}$ Fraunhofer IKTS, Fraunhofer Institute for Ceramic Technologies and Systems, 01277 Dresden, Germany \\ ${ }^{2}$ Institute of Materials Science (IfWW), Technische Universität Dresden, 01067 Dresden, Germany
}

Received: 7 December 2020

Accepted: 10 March 2021

Published online:

25 March 2021

(C) The Author(s) 2021

\begin{abstract}
Dense (Hf, Ta, Nb, Ti, V)C- and (Ta, Nb, Ti, V, W)C-based high-entropy carbides (HEC) were produced by three different sintering techniques: gas pressure sintering/sinter-HIP at $1900{ }^{\circ} \mathrm{C}$ and 100 bar Ar, vacuum sintering at $2250{ }^{\circ} \mathrm{C}$ and $0.001 \mathrm{bar}$ as well as SPS/FAST at $2000{ }^{\circ} \mathrm{C}$ and $60 \mathrm{MPa}$ pressure. The relative density varied from 97.9 to $100 \%$, with SPS producing $100 \%$ dense samples with both compositions. Grain size measurements showed that the substitution of $\mathrm{Hf}$ with $\mathrm{W}$ leads to an increase in the mean grain size of 5-10 times the size of the (Hf, Ta, Nb, Ti, V,)C samples. Vacuum-sintered samples showed uniform grain size distribution regardless of composition. EDS mapping revealed the formation of a solid solution with no intermetallic phases or element clustering. X-ray diffraction analysis showed the structure of mostly single-phase cubic highentropy carbides. Hardness measurements revealed that ( $\mathrm{Hf}, \mathrm{Ta}, \mathrm{Nb}, \mathrm{Ti}, \mathrm{V}) \mathrm{C}$ samples possess higher hardness values than $(\mathrm{Ta}, \mathrm{Nb}, \mathrm{Ti}, \mathrm{V}, \mathrm{W}) \mathrm{C}$ samples.
\end{abstract}

\section{Introduction}

Carbides of group IV, $\mathrm{V}$, and VI of transition metals ( $\mathrm{TiC}, \mathrm{ZrC}, \mathrm{NbC}, \mathrm{HfC}, \mathrm{TaC}, \mathrm{VC}, \mathrm{Cr}_{3} \mathrm{C}_{2}, \mathrm{Mo}_{2} \mathrm{C}$, and WC) are refractory carbides that combine high melting temperatures, high hardness, and high elastic modulus [1,2]. These refractory carbides are used as single carbides or in form of hard phases for tool steel or hardmetals (also known as cemented carbides or cermets). Bulk single carbides such as $\mathrm{WC}$ or $\mathrm{NbC}$ can be produced by solid-state sintering at temperatures of up to $2000{ }^{\circ} \mathrm{C}$ by various techniques $[3,4]$. When used as hard phases in hardmetals or cermets, liquid-phase sintering of mixtures with metallic binders such as $\mathrm{Co}, \mathrm{Ni}$, or Fe is carried out at temperatures between 1300 and $1500{ }^{\circ} \mathrm{C}$ mostly by vacuum sintering or sinter-HIP sintering [5].

Refractory monocarbide itself shows excellent properties such as high hardness and wear resistance [2]. However, there is a need for more stable materials to withstand an even broader range of extreme

Handling Editor: David Cann.

Address correspondence to E-mail: johannes.poetschke@ikts.fraunhofer.de 
environments. For such physical, chemical, and mechanical properties, a high entropy concept is added in this field of refractory carbides. These novel carbides are called high-entropy carbides (HEC) [5-18].

HECs are popularized from the concept of highentropy alloys (HEA) by Yeh (2004) [6]. Instead of one principal component, a HEA is a mixture of $4-5$ or more equimolar elements. This combination of equimolar elements enhances the mixing entropy $\left(\Delta S_{\text {mix }}=R^{*} \ln (N)\right.$, where $N$ is the number of elements, and $R$ is the gas constant) [6-8]. This enhanced mixing entropy improves the solubility among elements, thus preventing phase separation and defined compounds, leading to only a few phases or even a single-phase solid solution $[6,8]$. This solid solution has a unique lattice parameter, representing a new class of materials.

Published research work on HEC shows a significant increase in hardness and toughness and a decrease in thermal conductivity as compared to refractory monocarbides. HEC composition of (Hf$\mathrm{Ta}-\mathrm{Zr}-\mathrm{Nb}) \mathrm{C}$ had higher yield and failure strength as compared to $\mathrm{HfC}$ and $\mathrm{TaC}$ alone [9] and significantly enhanced nano-hardness $(36.1 \pm 1.6 \mathrm{GPa})$ as compared to hardest monocarbide (HfC, $31.5 \pm 1.6 \mathrm{GPa}$ ) [10]. (Zr-Nb-Ti-V)C prepared from fine-grained powder $(<3 \mu \mathrm{m})$ showed high nano-hardness $(30.3 \pm 0.7 \mathrm{GPa})$ and comparable high fracture toughness $\left(4.7 \pm 0.5 \mathrm{MPa} \mathrm{m}^{1 / 2}\right)$ [11]. The measured hardness of $(\mathrm{Ti}, \mathrm{Zr}, \mathrm{Nb}, \mathrm{Ta}, \mathrm{Mo}) \mathrm{C}$ was $25.3 \mathrm{GPa}$ at $9.8 \mathrm{~N}$ and $31.3 \mathrm{GPa}$ at $100 \mathrm{mN}$ indentation load [12].

A broad range of HEC compositions has been studied, but not all compositions can be synthesized to form a homogenous single-phase solution. Castle et al. [10] indicated that the lattice mismatch could contribute to single-phase solid-solution formation and also demonstrated that ( $\mathrm{Hf}, \mathrm{Ta}, \mathrm{Zr}, \mathrm{Nb}) \mathrm{C}$ formed single-phase more easily than (Hf, Ta, Zr, Ti)C. Nowadays, HEC is also being studied by implementing entropy descriptors [13], machine learning potentials [14], and hands-on approaches. In nearly all the reported works, HECs were produced by direct pressure-assisted sintering technologies such as spark plasma sintering/field-assisted sintering technologies (SPS/FAST) [12, 15-17] or hot pressing (HP) [18-20]. Information on sinterability using conventional industrial-like sintering technologies like vacuum sintering or gas pressure sintering (also known as sinter-HIP) is to our knowledge not published so far. The use of industrial furnaces would allow the fabrication of near-net-shape HEC parts with freedom in shapes by uniaxial pressing or other shaping technologies before sintering. Possible applications are wear parts, structural parts, or even cutting tools.

In this work, two different HEC materials were prepared by mixing five refractory carbides and subsequent sintering using gas pressure sintering, also known as sinter-HIP, vacuum sintering, and FAST/SPS. The influence of these sintering technologies on solid-solution formation, density, grain size, and basic mechanical properties was studied. The produced samples were characterized using scanning electron microscopy (SEM), energy-dispersive spectroscopy (EDS), and X-ray diffraction (XRD). The mechanical properties were determined by hardness and fracture toughness tests.

\section{Materials and methods}

Two multi-component carbide (HEC) materials were manufactured using a conventional powder technological route comprising the mixing of single carbides and subsequent sintering. Both HEC mixtures were made with an equiatomic composition of five metal carbide powders. Composition $\mathrm{A}$ is made only from cubic carbides $\mathrm{HfC}, \mathrm{TaC}, \mathrm{NbC}, \mathrm{TiC}$, and $\mathrm{VC}$, while composition $\mathrm{B}$ is free of $\mathrm{HfC}$ but contains hexagonal WC instead. The constitution of both compositions by weight percent is presented in Table 1. Details on powder manufacturers, particle sizes measured with Fisher Sub Sieve Sizer (FSSS), the specific surface area measured by BET method together with particle size $\mathrm{d}_{\mathrm{BET}}$ calculated from this specific surface area, assuming ball-like particles, and the oxygen contents as given by the manufacturer are listed in Table 2 .

Powder mixtures of compositions A and B were subjected to ball milling in n-heptane, vacuum dried, and sieve granulated. For sintering using sinter-HIP

Table 1 Details of the composition of HEC mixtures

\begin{tabular}{lllllll}
\hline Composition ID & \multicolumn{7}{l}{ Constitution (wt \%) } \\
\cline { 2 - 7 } & HfC & TaC & NbC & TiC & VC & WC \\
\hline A (Hf, Ta, Nb, Ti, V)C & 31.2 & 31.6 & 17.2 & 9.8 & 10.3 & - \\
B (Ta, Nb, Ti, V, W)C & - & 31.3 & 17.0 & 9.7 & 10.2 & 31.8 \\
\hline
\end{tabular}


and vacuum sintering (FPW280/600, FCT, Germany), the granulated powder mixtures were uniaxially pressed to plates (approx. $5 \times 17.5 \times 17.5 \mathrm{~mm}^{3}$ ) at $300 \mathrm{MPa}$. After this, the samples were sintered to form dense parts by (1) sinter-HIP at $1900{ }^{\circ} \mathrm{C}$ and 100 bar Ar pressure and (2) vacuum sintering at $2250{ }^{\circ} \mathrm{C}$ in a vacuum (0.001 to $0.8 \mathrm{bar}$ ). Temperatures and holding times are based on previous, unpublished work on different binderless carbides. Samples were also produced by (3) SPS (HHPD25, FCT, Germany) by means of consolidating the as-dried and sieve granulated powder at $2200{ }^{\circ} \mathrm{C}$ with $60 \mathrm{MPa}$ pressure.

All sintering methods employ heating, dwell time, and cooling steps for the consolidation of the samples. Figure 1 visualizes the different steps with the used temperatures and sintering times for each sintering method.

The density of sintered samples was measured according to ISO 3369 (Archimedes principle). Theoretical densities were calculated to the rule of mixture. For microstructural analysis, dense samples were ground and polished using different diamond slurries down to $1 \mu \mathrm{m}$. Images of microstructure were taken using the field emission scanning electron microscope (FESEM) ULTRA 55 (Carl Zeiss Microscopy), which was also used to perform energy-dispersive spectroscopy (EDS) element mappings (Oxford Instruments Ltd. NordlysS). Arithmetic average HEC grain size $\mathrm{d}_{\text {HEC }}$ was determined using the linear intercept method (ISO 4499-2). FESEM images at an appropriate magnification were used to determine $\mathrm{d}_{\mathrm{HEC}}$ by measuring at least 400 HEC grains. The phase composition of these samples was analyzed by X-ray diffraction (XRD) using a diffractometer (D8-Advance, Bruker AXS), operated with $\mathrm{Cu}-\mathrm{K} \alpha$ radiation with a LynxEye position-sensitive

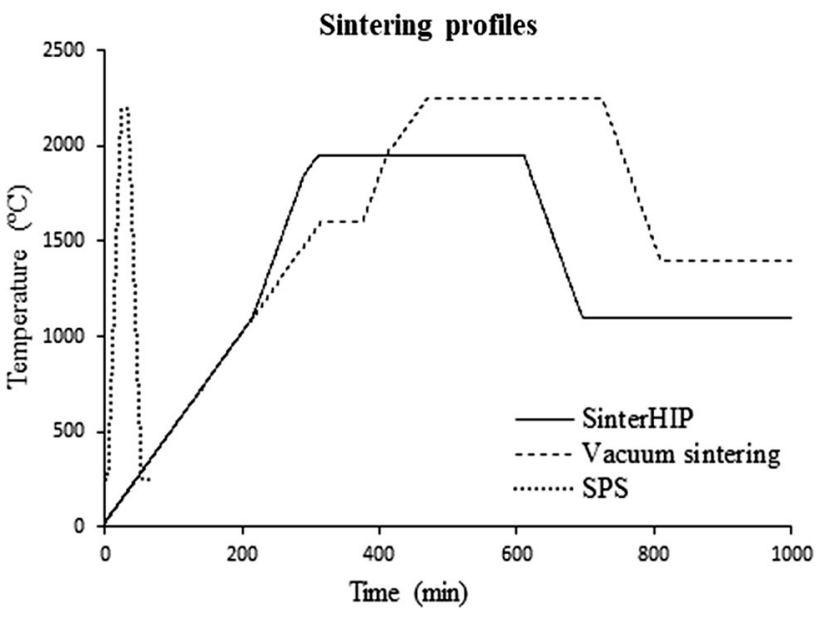

Figure 1 Different sintering profiles used to produce HEC samples.

detector and a nickel filter located in the primary beam. The Diffrac.EVA program and the JCPDS database (2015) were used for phase analysis. The lattice parameter was calculated using the TOPAS V5 (Bruker AXS) software.

Vickers hardness (HV 0.5) of sintered samples was measured according to ISO 3878 with a load of $4.9 \mathrm{~N}$. Fracture toughness $\left(K_{\mathrm{IC}}\right)$ was calculated from measuring Vickers indentation crack length using Shetty equation [21]. Young's modulus was calculated from the measured modulus of indentation according to EN ISO 14577, using the instrumented indentation tester MCT (Mikro-Combi-Tester, Anton Paar) and the estimated sample's Poisson ratio of 0.18. The following measurement parameters were used: rate of loading of $1.5 \mathrm{~N} / \mathrm{min}$, maximum force $0.5 \mathrm{~N}$, dwell time $10 \mathrm{~s}$. Correction of tip shape of the Vickers indenter was done by determining the area function in BK7 glass. The force-displacement curve was evaluated using the Oliver and Pharr model.

Table 2 Powder details with the supplier, particle sizes, specific surface area, and oxygen contents

\begin{tabular}{llllll}
\hline Powders & Supplier & Particle size $d_{\mathrm{FSSS}}(\mu \mathrm{m})$ & Specific surface area BET $\left(\mathrm{m}^{2} / \mathrm{g}\right)$ & Particle size $\mathrm{d}_{\mathrm{BET}}(\mathrm{nm})$ & Oxygen content $(\mathrm{wt} \%)$ \\
\hline HfC & ABCR & 1.8 & 0.8 & 606 & 0.32 \\
$\mathrm{TaC}$ & H.C. Starck & 1.0 & 1.1 & 366 & 0.13 \\
$\mathrm{NbC}$ & GTP & 1.2 & 1.2 & 639 & 0.25 \\
$\mathrm{TiC}$ & H.C. Starck & 2.4 & 2.0 & 619 & 0.37 \\
VC & H.C. Starck & 1.2 & 3.0 & 350 & 0.80 \\
WC & H.C. Starck & 0.5 & 2.6 & 149 & 0.26 \\
\hline
\end{tabular}




\section{Results and discussion}

\section{Microstructure of produced materials}

Formation of fully dense high-entropy carbides can be challenging because of the high melting and sintering temperatures of individual refractory carbides. Nevertheless, high-density high-entropy carbides were produced by all three used sintering methods with both compositions. Archimedes density and the relative density, which is based on the calculated composite density according to the rule of mixture with theoretical density for composition A of $9.26 \mathrm{~g} /$ $\mathrm{cm}^{3}$ and composition $\mathrm{B}$ of $9.85 \mathrm{~g} / \mathrm{cm}^{3}$, are given in Table 3.

Slightly different relative densities were obtained for each HEC material produced by the different sintering methods, as can be seen from Table 3 . Sample of composition A produced by the sinter-HIP process $(99.7 \%)$ was denser than sample of composition B (97.9\%) produced with the same process. However, almost identical relative densities were obtained for both samples by vacuum sintering $(99.5 \%)$ and by SPS (100\%). The formation of the densest samples by SPS can be expected due to the high heating rates $(100 \mathrm{~K} / \mathrm{min})$ in comparison with the systems with external heating in sinter-HIP (5-10 K/min) and vacuum sintering (5-10 K/min) (Fig. 1) as well as to the high applied uniaxial pressure of $60 \mathrm{MPa}$ during heating and dwell time.

Microstructural images obtained by FESEM (Fig. 2) are in accordance with density measurements (Table 3). Sinter-HIP- and vacuum-sintered samples of composition A and B both show porosity as they were not $100 \%$ dense. SPS-sintered samples of composition A and B are $100 \%$ dense samples; hence, they show only very few "pore-like" black spots.
The secondary electron micrographs of sample produced from composition $\mathrm{A}$ and $\mathrm{B}$ exhibited in Fig. 2 show HEC grains (visible due to orientation contrast), black spots (mostly pores) as well as bright spots. In sinter-HIP sample of composition A, only very few small black spots, i.e., pores are visible. However, in the vacuum-sintered sample of composition A black spots with sizes ranging from 1 to $2.5 \mu \mathrm{m}$ and some bright spots can be seen. These bright spots are much more pronounced in SPS-sintered sample of composition A.

EDS mappings done on samples produced from composition A are presented in Fig. 3.

EDS mappings reveal that in all samples, all-metal elements are present in the solid-solution high-entropy carbide. However, as mentioned some nonHEC grains can be seen as well. In sinter-HIP sample as well as in vacuum-sintered sample of composition A, white spots correlate with increased amount of Ta. In both cases, these grains are most likely residual Tacarbide grains that have not dissolved within the HEC phase. In the SPS-sintered sample of composition A, most white spots in the secondary electron micrographs correlate with increased amount of both $\mathrm{Hf}$ and $\mathrm{O}$, indicating Hf-oxide. The presence of these segregations in composition A sintered by SPS originates assumingly from the unfinished reduction of oxide phases. It is expected that due to the fast heating and densification rate in SPS, the reduction of very stable Hf-oxides (melting point of $2758{ }^{\circ} \mathrm{C}$ [1]) is most likely hindered due to the fast formation of dense material resulting in residual Hf-oxides. A similar effect was observed in the SPS densification of pure $\mathrm{HfC}$ [22] where the complete reduction of $\mathrm{HfO}_{2}$ was found only at $2400{ }^{\circ} \mathrm{C}$ [22].

Overall, EDS mappings of samples of composition A produced by sinter-HIP and vacuum sintering demonstrate the uniform distribution of elements,

Table 3 Density measurement of samples from composition A and B produced by different sintering techniques, measurement error is $\pm 0.02 \mathrm{~g} / \mathrm{cm}^{3}$

\begin{tabular}{lllr}
\hline Compositions & Sintering processes and conditions & Obtained density $\left(\mathrm{g} / \mathrm{cm}^{3}\right)$ & Relative density $(\%$ theor.) \\
\hline A (Hf, Ta, Nb, Ti, V)C & Sinter-HIP $\left(1900{ }^{\circ} \mathrm{C} / 100\right.$ bar Ar) & 9.24 & 99.7 \\
& Vacuum sintering $\left(2250{ }^{\circ} \mathrm{C} / 0.001\right.$ bar $)$ & 9.22 & 99.5 \\
& SPS $\left(2000{ }^{\circ} \mathrm{C} / 60 \mathrm{MPa}(600 \mathrm{bar})\right)$ & 9.26 & 100.0 \\
$\mathrm{~B}(\mathrm{Ta}, \mathrm{Nb}, \mathrm{Ti}, \mathrm{V}, \mathrm{W}) \mathrm{C}$ & Sinter-HIP $\left(1900{ }^{\circ} \mathrm{C} / 100 \mathrm{bar} \mathrm{Ar}\right)$ & 9.61 & 97.9 \\
& Vacuum sintering $\left(2250{ }^{\circ} \mathrm{C} / 0.001\right.$ bar $)$ & 9.76 & 99.5 \\
& SPS $\left(2000{ }^{\circ} \mathrm{C} / 60 \mathrm{MPa}(600 \mathrm{bar})\right)$ & 9.85 & 100.0 \\
\hline
\end{tabular}


(a) Sample A - SinterHIP $\left(1900^{\circ} \mathrm{C}\right)$

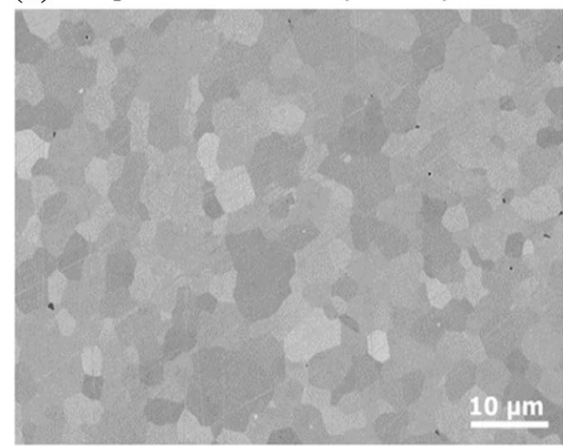

(d) Sample B - SinterHIP $\left(1900^{\circ} \mathrm{C}\right)$

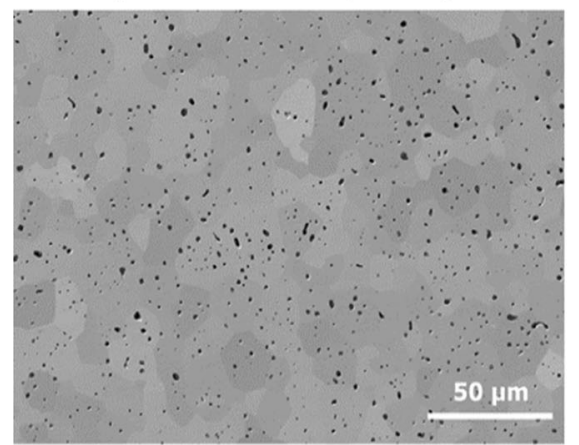

(b) Sample A - Vacuum Sintering $\left(2250^{\circ} \mathrm{C}\right)$

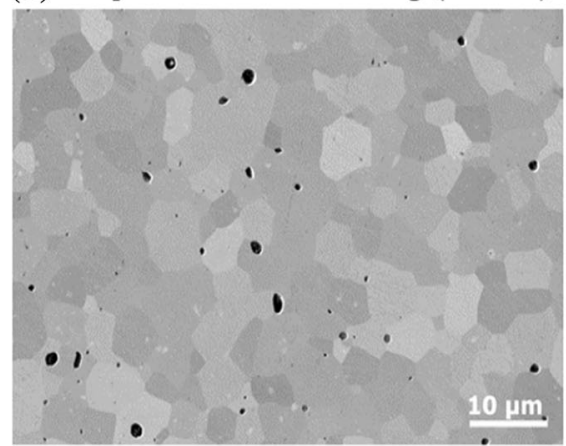

(e) Sample B - Vacuum Sintering $\left(2250^{\circ} \mathrm{C}\right)$ (c) Sample A-SPS $\left(2000^{\circ} \mathrm{C}\right)$

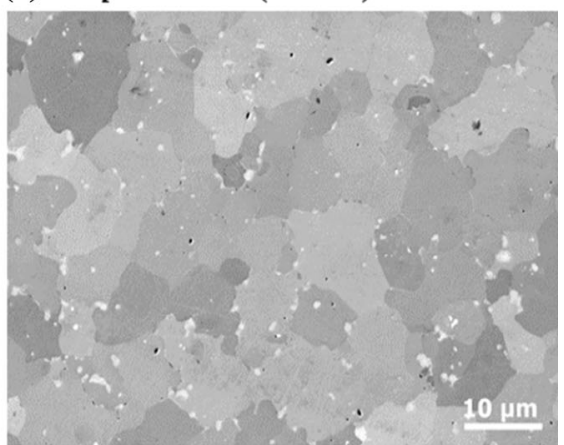

(f) Sample B-SPS $\left(2000^{\circ} \mathrm{C}\right)$
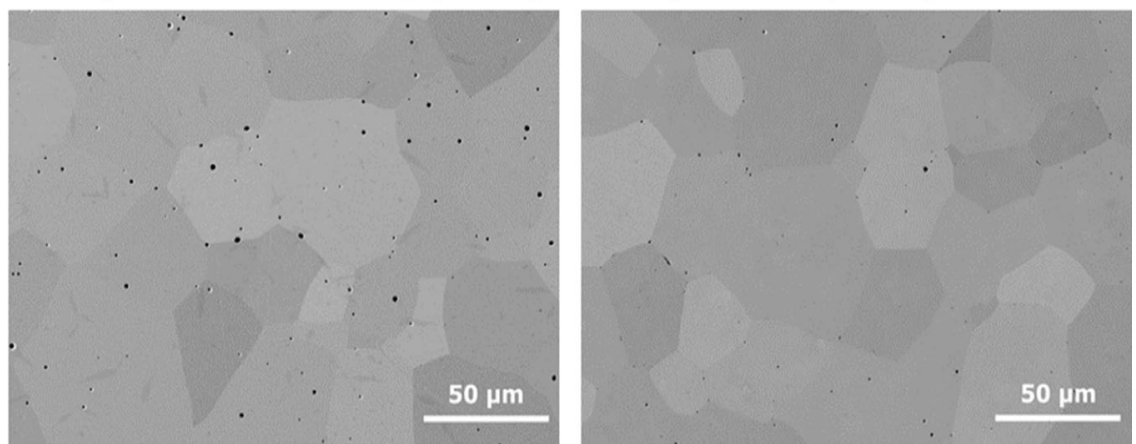

Figure 2 Micrographs of samples A and B sintered at different temperatures using sinter-HIP, vacuum sintering, and SPS methods.

thus showing the homogenous solid-solution formation of HEC grains.

With the absence of $\mathrm{HfC}$ in composition B, no bright spots can be observed in Fig. $2 d-f$. The size of black spots in sinter-HIP- and vacuum-sintered samples of composition B is around 2.5 to $5 \mu \mathrm{m}$, which is twice as big compared to the black spots in samples of composition A. SPS sample of composition A shows small black spots as well. These black spots could either be pores or carbides with a low density. Corresponding EDS mappings are presented in Fig. 4. Here, the presence of "black spots" can be correlated with low amounts of free carbon. This confirms that the "black spots" found in the micrograph (Fig. 2) for samples produced with sinter-HIP and vacuum sintering are not all pores but also segregations of unbound/excess carbon. In contrast to samples produced from composition A, no oxides were detected in all sintered samples with composition B. However, due to the addition of $\mathrm{W}$ in composition $\mathrm{B}$, the homogenous solid-solution range of the HEC is maybe narrowed, resulting in the formation of free carbon with the chosen equiatomic composition and resulting carbon content used in composition B.
Furthermore, a difference in grain sizes in samples of composition A and B can be noticed due to differences in composition and sintering processes. Mean and median grain sizes, together with span of grain size distribution for all compositions and sintering methods, were therefore measured and are given in Table 4.

In general, grain growth is a thermally activated process. Thus, the sinter-HIP process, which has the lowest sintering temperature of $1900{ }^{\circ} \mathrm{C}$ as compared to vacuum sintering at $2250{ }^{\circ} \mathrm{C}$ or SPS at $2000{ }^{\circ} \mathrm{C}$ resulted in the smallest overall mean grain sizes for both compositions $(2.59 \mu \mathrm{m}$ for composition $\mathrm{A}$ and $15.18 \mu \mathrm{m}$ for composition B). This is despite the longer dwell time (240 $\mathrm{min})$ in the case of sinter-HIP process in comparison with the SPS (10 min). SPSsintered samples have interestingly quite a large grain size for both compositions, despite the shorter dwell time and lower sintering temperature as compared to vacuum-sintered samples. In particular, for composition A, a possible explanation could be that the presence of unreduced oxides facilitates faster grain growth, resulting in the largest grain size found for composition A. 

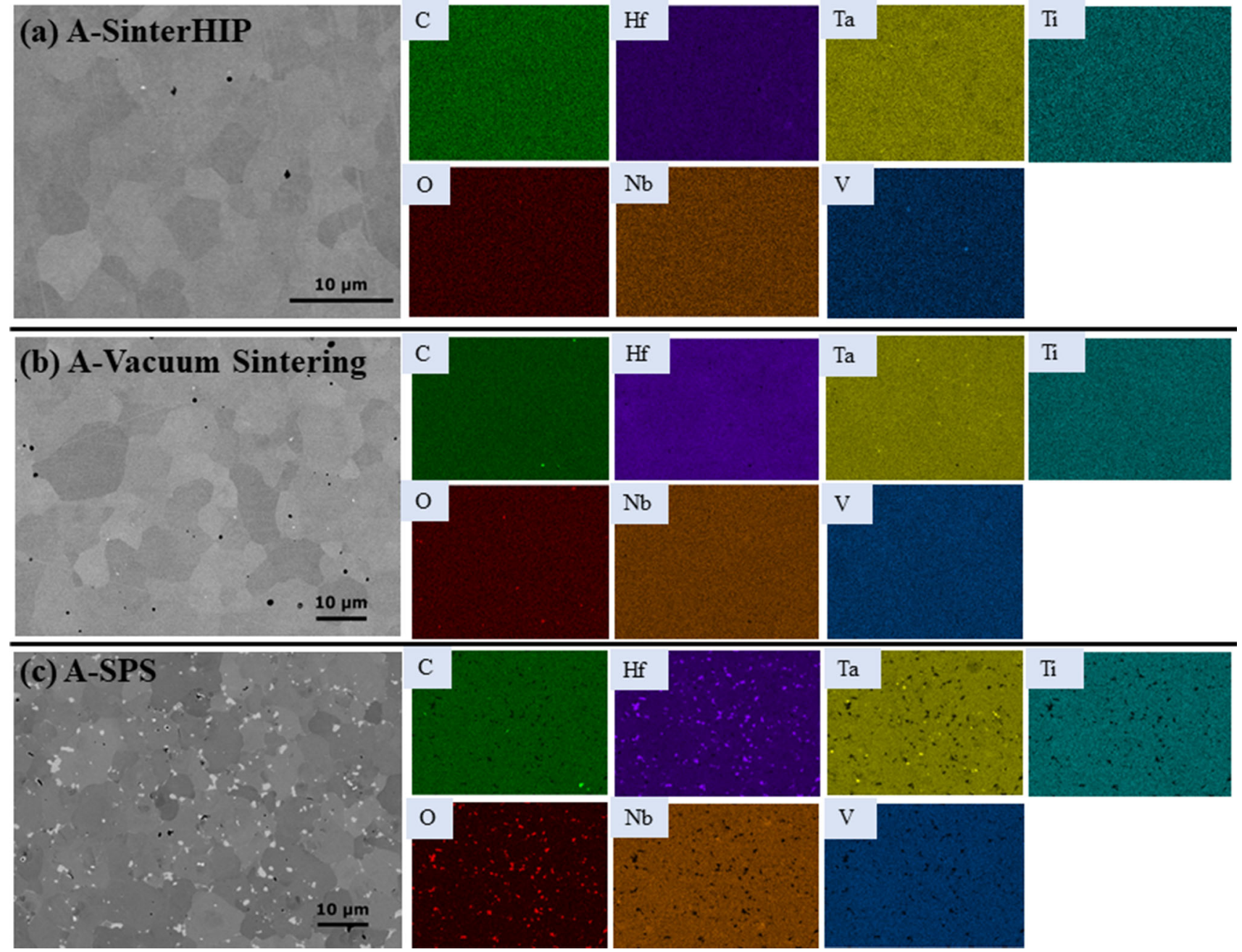

Figure 3 EDS mapping of samples produced from composition A (Hf, Ta, Ti, Nb, V)C produced by a sinter-HIP, b vacuum sintering, and c SPS.

Furthermore, samples with composition A (Hf, Ta, $\mathrm{Nb}, \mathrm{Ti}, \mathrm{V}) \mathrm{C}$ show 5-10 times smaller grain sizes than samples with composition $\mathrm{B}(\mathrm{Ta}, \mathrm{Nb}, \mathrm{Ti}, \mathrm{V}, \mathrm{W}) \mathrm{C}$. The large differences in the grain size suggest that the diffusion coefficients are different for the two systems. This could relate to the non-cubic structure of the WC in the starting mixture, which seemed to lead to higher interdiffusion of elements, resulting in larger HEC grain sizes. However, this needs some more detailed investigations.

In accordance with this, vacuum-sintered sample of composition B (containing WC) has a mean grain size of $33.7 \mu \mathrm{m}$ as compared to corresponding sample of composition A (no WC) with a mean grain size of just $3.5 \mu \mathrm{m}$. However, even though the grain size is larger, a slightly narrower grain size distribution is observed in vacuum-sintered sample of composition
B compared to the vacuum-sintered sample of composition A. For all samples, no abnormal large platelet grains are observed in contrast to pure binderless WC samples produced from similar WC powders as used in composition $\mathrm{B}$ and which were prepared with similar sintering regimes [4].

X-ray diffraction (XRD) was done on as-pressed samples (not yet sintered), and on all sintered samples (sinter-HIP, vacuum sintering, and SPS). XRD pattern of composition $\mathrm{A}(\mathrm{Hf}, \mathrm{Ta}, \mathrm{Ti}, \mathrm{Nb}, \mathrm{V}) \mathrm{C}$ is shown in Fig. 5. XRD peaks of the as-pressed sample show all the diffraction patterns of the used monocarbides. After sintering, all peaks relating to individual carbide phases have disappeared, leaving one set of a new cubic phase regardless of the process used. This phase has the $\mathrm{NaCl}(\mathrm{Fm}-3 \mathrm{~m})$ structure 


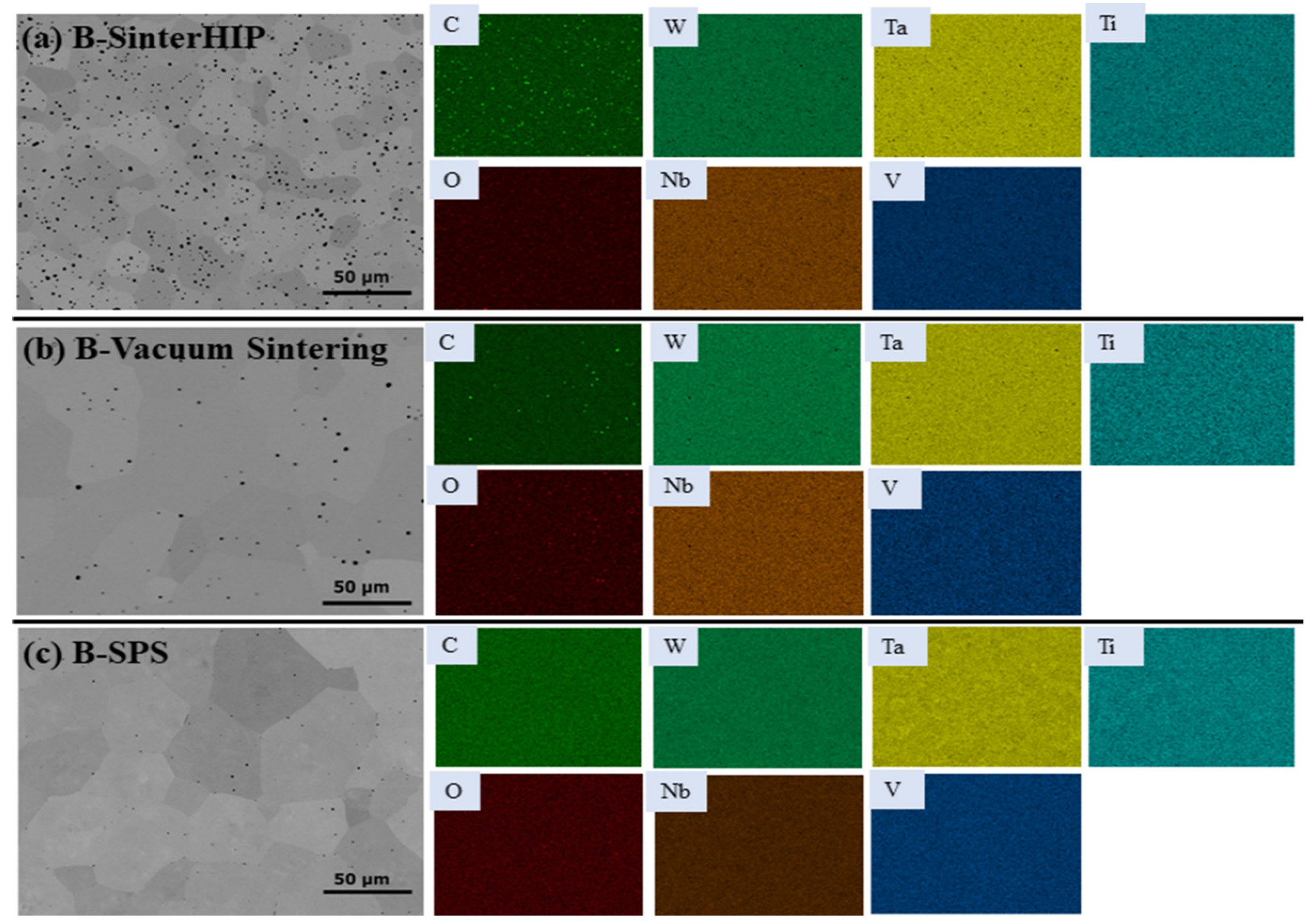

Figure 4 EDS mapping of samples produced from composition B (Ta, Nb, Ti, V, W)C by a sinter-HIP, b vacuum sintering, and $\mathbf{c}$ SPS.

Table 4 Grain size measurement of samples A and B produced using different sintering techniques

\begin{tabular}{|c|c|c|c|c|c|c|}
\hline Compositions & Sintering processes & Mean grain size $(\mu \mathrm{m})$ & $\mathrm{d}_{10}(\mu \mathrm{m})$ & $\mathrm{d}_{50}(\mu \mathrm{m})$ & $\mathrm{d}_{90}(\mu \mathrm{m})$ & $\operatorname{Span}\left(\mathrm{d}_{90}-\mathrm{d}_{10}\right) / \mathrm{d}_{50}$ \\
\hline \multirow[t]{3}{*}{ A (Hf, Ta, Nb, Ti, V)C } & Sinter-HIP & $2.59 \pm 0.16$ & 0.8 & 2.2 & 4.8 & 1.8 \\
\hline & Vacuum & $3.46 \pm 0.18$ & 1.3 & 3.2 & 5.9 & 1.5 \\
\hline & SPS & $5.62 \pm 0.38$ & 1.4 & 4.9 & 10.9 & 2.0 \\
\hline \multirow[t]{3}{*}{$\mathrm{B}(\mathrm{Ta}, \mathrm{Nb}, \mathrm{Ti}, \mathrm{V}, \mathrm{W}) \mathrm{C}$} & Sinter-HIP & $15.20 \pm 0.82$ & 4.9 & 13.8 & 26.3 & 1.6 \\
\hline & Vacuum & $33.70 \pm 1.80$ & 14.4 & 31.7 & 59.4 & 1.4 \\
\hline & SPS & $31.20 \pm 1.81$ & 10.0 & 28.4 & 53.9 & 1.5 \\
\hline
\end{tabular}

The error given for the mean value is the confidential interval $(95 \%)$

and shows the formation of a unique solid-solution HEC phase.

In both the SPS as well as in the sinter-HIP sample, small amounts of a second phase are found as well. In case of the SPS samples, these peaks could be identified as $\mathrm{HfO}_{2}$, which corresponds to the EDS mapping shown in Fig. 3 . In the sinter-HIP sample, another cubic phase (Fm-3 m, $a=5.584 \AA$ ) could be found, where some reflection corresponds quite well with similar phases found by Caste et al. [10] and Feng et al. [23], who studied the same composition. Since no powder diffraction file suited the found peaks, we assume that either a complex oxide or a second medium or high-entropy carbide phase formed. Due to the fact that no oxide phase was visible in the EDS mapping in Fig. 3 and that broader peaks would be expected if very fine oxides would be 


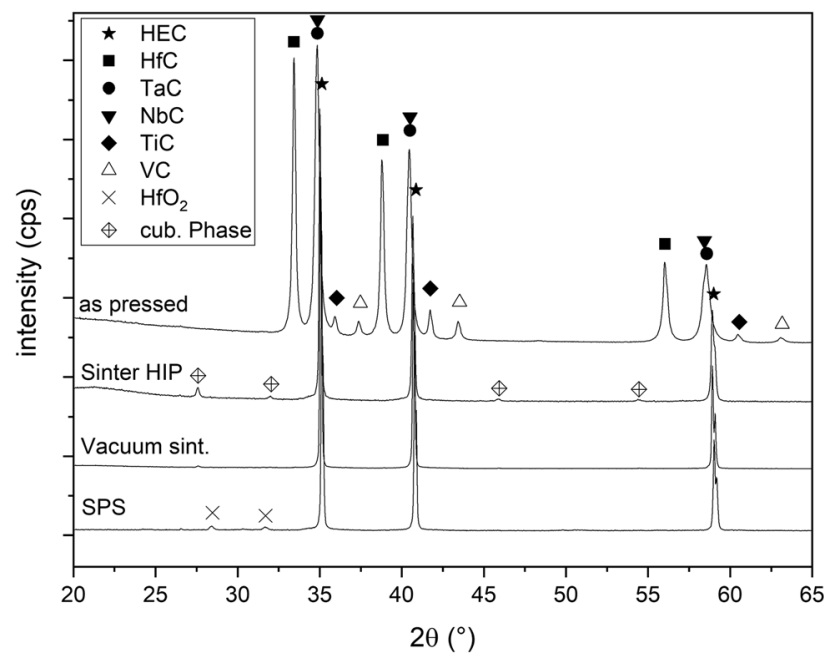

Figure 5 X-ray diffraction pattern of samples with composition A with 2 Theta ranging from 20 to 65 degrees.

present, we assume that these peaks belong to a secondary cubic carbide phase.

Like in samples of composition A, the as-pressed diffraction pattern of composition B in Fig. 6 also corresponds to the diffraction patterns of the used individual cubic monocarbides. But unlike composition A (Hf, Ta, Ti, Nb, V)C, composition B (Ta, Ti, Nb, $\mathrm{V}, \mathrm{W}) \mathrm{C}$ contains hexagonal $\mathrm{WC}$ in the initial stage. However, this crystallographic difference did not hinder the formation of a cubic single-phase solid solution, as can be seen in sintered samples, regardless of the sintering method used.

As in composition A also in composition B, the same secondary cubic phase was found for the

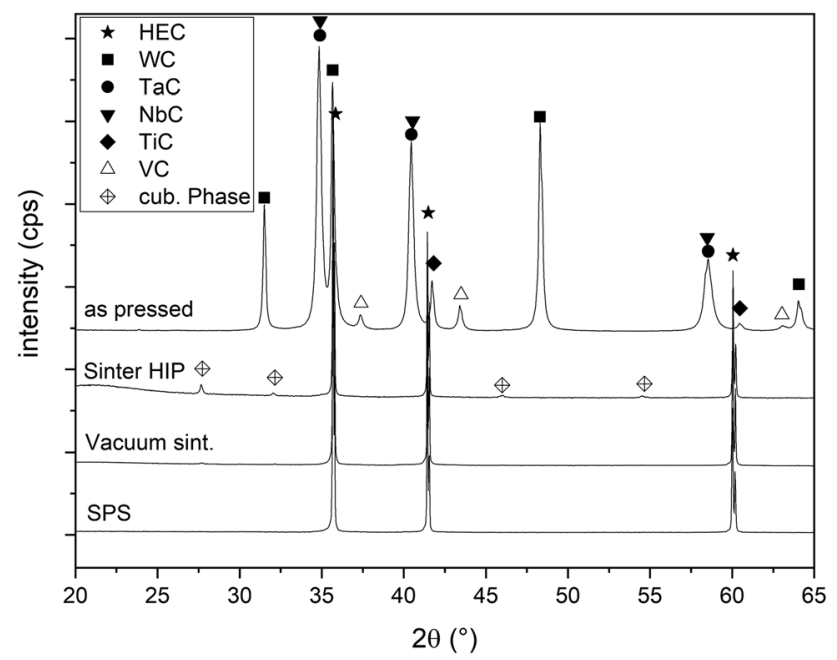

Figure 6 X-ray diffraction pattern of samples with composition B with two Theta ranging from 20 to 65 degrees.
sinter-HIP-sintered sample. Due to the differences in composition of the two studied HECs, this leads to the assumption that the additional cubic phase has to be free of $\mathrm{Hf}$ and $\mathrm{W}$, since these are the differentiating elements in composition A and B.

Further, the lattice parameter of the produced HEC phases from compositions A and B synthesized by the three used sintering processes is summarized in Table 5. The formation of a rock-salt structure with space group $\mathrm{Fm}-3 \mathrm{~m}$ indicates that the five metal elements ( $\mathrm{Hf}, \mathrm{Ta}, \mathrm{Nb}, \mathrm{Ti}, \mathrm{V}$ ) of composition $\mathrm{A}$ and ( $\mathrm{Ta}, \mathrm{Ti}, \mathrm{Nb}, \mathrm{V}, \mathrm{W}$ ) of composition $\mathrm{B}$ share cation position while the $\mathrm{C}$ atoms occupy the anion position.

From Table 5, it can be deduced that the lattice parameter for samples of composition $\mathrm{A}$ is in general larger than the lattice parameter for samples of composition B. The lattice parameter is dependent on the radii of the used metal ions. Because of the larger radius of Hf in comparison with $\mathrm{W}$ [24], which was used in composition $\mathrm{A}$, the medium ion radius (rule of mixture) in composition A should be larger and therefore the lattice parameter should be increased in comparison with composition B. All samples regardless of their compositions and sintering processes possess cubic structures like the majority of their corresponding single carbides such as $\mathrm{HfC}, \mathrm{TaC}$, $\mathrm{NbC}, \mathrm{TiC}, \mathrm{VC}$. The study by Harrington [17], who also manufactured high-entropy carbides with (Hf, $\mathrm{Ta}, \mathrm{Nb}, \mathrm{Ti}, \mathrm{V}) \mathrm{C}$ and $(\mathrm{Ta}, \mathrm{Nb}, \mathrm{Ti}, \mathrm{V}, \mathrm{W}) \mathrm{C}$ via SPS at $2200{ }^{\circ} \mathrm{C}$, reported similar lattice parameters of $4.42 \AA$ and $4.36 \AA$, respectively. According to Vegard's law, the calculated lattice parameter for composition $\mathrm{A}$ (Hf, $\mathrm{Ta}, \mathrm{Nb}, \mathrm{Ti}, \mathrm{V}) \mathrm{C}$ is $4.411 \AA$, and $4.363 \AA$ for composition $\mathrm{B}(\mathrm{Ta}, \mathrm{Nb}, \mathrm{Ti}, \mathrm{V}, \mathrm{W}) \mathrm{C}$. These are calculated from the lattice parameters of the single carbides: HfC (4.637 ̊) [10], TaC (4.452 ̊) [10], NbC $(4.470 \AA)$ [10], TiC (4.326 ̊) [10], VC (4.170 ̊) [25] and cubic WC (4.398 $\AA$ ) [26]. Thus, the measured lattice parameters are slightly smaller than the calculated ones, most likely due to distortions within the HEC crystals. The obtained lattice parameters are larger than $\mathrm{VC}$ and $\mathrm{TiC}$ but smaller than the other used single monocarbides.

There is a slight change in the lattice parameter as a function of sintering methods. In composition A, SPSsintered sample has the smallest lattice parameter. This could be caused due to the presence of small amounts of Hf-oxide, and also some residual $\mathrm{TaC}$, resulting in a slightly lower amount of $\mathrm{Ta}$ and $\mathrm{Hf}$ within the HEC grains. In composition B, the sinter- 
Table 5 Lattice parameter of the cubic solid solution of the $\mathrm{NaCl}$-structure type (Fm-3 m) for the sintered samples A and B

\begin{tabular}{lll}
\hline Composition & Sintering process & Lattice parameter $(\AA)$ \\
\hline Sample A (Hf, Ta, Nb, Ti, V)C & Sinter-HIP & $4.4255 \pm 0.001$ \\
& Vacuum sintering & $4.4273 \pm 0.001$ \\
& SPS & $4.4243 \pm 0.001$ \\
Sample B (Ta, Nb, Ti, V, W)C & Sinter-HIP & $4.3532 \pm 0.001$ \\
& Vacuum sintering & $4.3575 \pm 0.001$ \\
& SPS & $4.3586 \pm 0.001$ \\
\hline
\end{tabular}

HIP-sintered sample has the smallest lattice parameter.

\section{Mechanical properties of produced materials}

Vickers hardness tests were performed on all samples to further characterize the obtained HEC in regard to mechanical properties. The values for hardness and toughness (if measurable) are summarized in Table 6.

In Table 6, the observed hardness values of samples from composition A and B seem to correlate with the grain size measurements. The grain sizes of samples of composition A are 5 to 10 times smaller than samples from composition B. Among composition A, the sinter-HIP-sintered sample has the lowest hardness compared to the vacuum-sintered and SPSsintered samples despite having smaller grain size. The exact reason behind this cannot be explained at this moment and has to be studied further.

For the measurement of hardness, the size of indentation was around $19 \mu \mathrm{m}$. For samples of composition $\mathrm{A}$, the grain size varied from 2.6 to $5.6 \mu \mathrm{m}$ which means that the indentation covers multiple grains. With the same indentation size but larger grain sizes of samples of composition B, which varied from 15.2 to $33.7 \mu \mathrm{m}$, here mostly single grains were measured. Usage of higher loads such as HV10, HV5, or even HV 1 was not applicable because of the brittle nature of samples. Thus, when comparing the hardness values it has to be considered that in case of samples of composition A hardness of the polycrystalline HEC (including grain boundaries) and in case of samples from composition B hardness of mostly single HEC crystals (without a significant amount of grain boundaries) was measured. The samples were quite brittle and a measurement of fracture toughness by indentation method was only possible in samples of composition B produced by sinter-HIP and SPS. The measured $\mathrm{K}_{1 \mathrm{C}}$ values are comparable to binderless $\mathrm{NbC}$ [3].

Comparing the values with microhardness hardness values of bulk monocarbides with similar grain sizes, it can be deduced that a higher hardness can be achieved with the produced HEC compositions. This is based on research done on pure $\mathrm{NbC}$ samples, which showed microhardness hardness values between 1650 HV1 and 1700 HV1 [3]. Literature values for the microhardness of other carbides, such as $\mathrm{WC}, \mathrm{TaC}$ and $\mathrm{NbC}$, are in the range of 1800 to 2400 $\mathrm{HV}$ and for $\mathrm{TiC}, \mathrm{ZrC}$, and $\mathrm{HfC}$ in the range of 2600 to $3200 \mathrm{HV}$ [27]. The prepared HEC materials could thus be studied as novel hard phases in hardmetals or cermets, as studied by us in [28].

Furthermore, the Young's modulus was studied using the instrumented indentation method. Here, for composition $\mathrm{A}$ and $\mathrm{B}$, the densest samples

Table 6 Physical properties of dense samples produced from compositions A and B and three different sintering methods (n.m.: not measurable)

\begin{tabular}{llll}
\hline Composition & Sintering techniques & Hardness $\left(\mathrm{HV}_{0.5}\right)$ & Fracture toughness $\mathrm{K}_{1 \mathrm{C}}\left(\mathrm{MPa} \mathrm{m}^{1 / 2}\right)$ \\
\hline $\mathrm{A}(\mathrm{Hf}, \mathrm{Ta}, \mathrm{Nb}, \mathrm{Ti}, \mathrm{V}) \mathrm{C}$ & Sinter$-\mathrm{HIP}\left(1900^{\circ} \mathrm{C}\right)$ & $2437 \pm 47$ & n.m \\
& Vacuum sintering $\left(2250^{\circ} \mathrm{C}\right)$ & $2573 \pm 86$ & n.m \\
& SPS $\left(2000^{\circ} \mathrm{C}\right)$ & $2569 \pm 56$ & n.m \\
$\mathrm{B}(\mathrm{Ta}, \mathrm{Nb}, \mathrm{Ti}, \mathrm{V}, \mathrm{W}) \mathrm{C}$ & Sinter-HIP $\left(1900^{\circ} \mathrm{C}\right)$ & $1873 \pm 80$ & 3.8 \\
& Vacuum sintering $\left(2250^{\circ} \mathrm{C}\right)$ & $2217 \pm 40$ & n.m \\
& SPS $\left(2000^{\circ} \mathrm{C}\right)$ & $2021 \pm 56$ & 3.4 \\
\hline
\end{tabular}


showing a pure HEC phase formation were chosen, since porosity and third phases influence the Young's modulus. For composition A, the sinter-HIP produced sample showed a Young's modulus of $471 \pm 32 \mathrm{GPa}$. For the via vacuum sintering obtained samples from composition B, a Young's modulus of $490 \pm 21 \mathrm{GPa}$ was measured. Both values are in good agreement with the same compositions prepared solely via SPS [13].

\section{Conclusion and outlook}

Dense high-entropy carbides (HEC) were produced using three different sintering techniques (sinter-HIP, vacuum sintering, and SPS). Two different HEC compositions were manufactured, one using five different cubic monocarbides of $\mathrm{HfC}, \mathrm{TaC}, \mathrm{NbC}, \mathrm{TiC}$, $\mathrm{VC}$, and the other substituting cubic HfC with hexagonal WC. The relative density of the HEC samples varied from 97.9 to $100 \%$, with samples sintered from SPS yielding $100 \%$, and vacuum sintering yielding $99.5 \%$ regardless of compositions. Samples with starting carbides with cubic structure exhibit 5-10 times smaller grain sizes than samples containing the non-cubic WC-powder in the initial composition. XRD analysis and EDS mapping showed for all samples the formation of a unique solid solution. However, small amounts of Hf-oxide were still present in SPS-sintered samples, indicating an unfinished reduction of the surface oxides due to the fast densification. ( $\mathrm{Hf}, \mathrm{Ta}, \mathrm{Nb}, \mathrm{Ti}, \mathrm{V}$ ) C samples showed a higher hardness than samples containing W instead of Hf ( 2570 HV0.5 vs. 2220 HV0.5). Thus, the present study showed that HEC can be produced in industrial-like vacuum or sinter-HIP furnaces, which opens this novel material for industrial use through the press and sinter technology.

To study the HEC materials further, the measurement of fracture toughness, done by Single-Edge- $\mathrm{V}$ Notched Beam (SEVNB)-based techniques, is planned. Also, further investigations with other HEC compositions, smaller starting powder grain sizes, and different synthesis technologies to test the sintering of pre-produced HEC powders are planned to shed light on the main mechanism for higher hardness values. Since the carbon content is seen as a not yet investigated parameter which should influence grain size, lattice parameters, and mechanical properties, $\mathrm{C}$ deficient HEC compositions are planned to be studied as well.

\section{Acknowledgements}

The authors thank Markus Mayer for his help in sample preparation and assistance in samples characterization.

\section{Funding}

Open Access funding enabled and organized by Projekt DEAL.

\section{Declarations}

Conflicts of interest The authors declare no conflict of interest.

Open Access This article is licensed under a Creative Commons Attribution 4.0 International License, which permits use, sharing, adaptation, distribution and reproduction in any medium or format, as long as you give appropriate credit to the original author(s) and the source, provide a link to the Creative Commons licence, and indicate if changes were made. The images or other third party material in this article are included in the article's Creative Commons licence, unless indicated otherwise in a credit line to the material. If material is not included in the article's Creative Commons licence and your intended use is not permitted by statutory regulation or exceeds the permitted use, you will need to obtain permission directly from the copyright holder. To view a copy of this licence, visit http://creativecommons.org/licen ses/by/4.0/.

\section{References}

[1] Wuchina E, Opila E, Opeka M, Fahrenholtz W, Talmy I (2007) UHTCs: ultra-high temperature ceramic materials for extreme environment applications. ElectrochemSoc Interface 16:30-36

[2] Pierson HO (1996) Handbook of refractory carbides and nitrides. Noyes Publication, New Jersey

[3] Pötschke J, Vornberger A, Berger C (2018) Enhancement of hardness in niobium carbide composites. IntConf Powder Metall Part Mater 2018:522-532 
[4] Pötschke J, Richter V, Michaelis A (2015) Fundamentals of sintering nanoscaled binderless hardmetals. Int $\mathrm{J}$ Refract Metal Hard Mater 49:124-132

[5] Fang ZZ, Koopman MC, Wang H (2014) Cemented tungsten carbide hardmetal-an introduction. Comprehensive hard materials. Elsevier, Amsterdam, pp 123-137

[6] Yeh JW (2006) Recent progress in high-entropy alloys. Ann ChimSci Mat 31(6):633-648

[7] Murty BS, Yeh J-W, Ranganathan S, Bhattacherjee PP (2019) High entropy alloys. Elsevier, Amsterdam

[8] Porter DA, Easterling KE, Sherif M (2009) Phase transformations in metals and alloys, 3rd edition (Revised reprint), 3rd edn. CRC Press, Hoboken

[9] Csanádi T, Castle E, Reece MJ, Dusza J (2019) Strength enhancement and slip behaviour of high-entropy carbide grains during micro-compression. Sci Rep 9(1):10200

[10] Castle E, Csanádi T, Grasso S, Dusza J, Reece M (2018) Processing and properties of high-entropy ultra-high temperature carbides. Sci Rep 8(1):8609

[11] Ye B, Wen T, Nguyen MC, Hao L, Wang CZ, Chu Y (2019) First-principles study, fabrication and characterization of (Zr0.25Nb0.25Ti0.25V0.25)C high-entropy ceramics. Acta Mater 170:15-23

[12] Wang K, Chen L, Xu C, Zhang W, Liu Z, Wang Y et al (2020) Microstructure and mechanical properties of (TiZrNbTaMo)C high-entropy ceramic. J Mater SciTechnol 39:99-105

[13] Sarker P, Harrington T, Toher C, Oses C, Samiee M, Maria JP et al (2018) High-entropy high-hardness metal carbides discovered by entropy descriptors. Nat Commun 9(1):4980

[14] Dai F-Z, Wen B, Sun Y, Xiang H, Zhou Y (2020) Theoretical prediction on thermal and mechanical properties of high entropy ( $\mathrm{Zr} 0.2 \mathrm{Hf} 0.2 \mathrm{Ti} 0.2 \mathrm{Nb} 0.2 \mathrm{Ta} 0.2) \mathrm{C}$ by deep learning potential. J Mater SciTechnol 43:168-174

[15] Yan X, Constantin L, Lu Y, Silvain J-F, Nastasi M, Cui B (2018) (Hf 0.2 Zr 0.2 Ta 0.2 Nb 0.2 Ti 0.2)C high-entropy ceramics with low thermal conductivity. J Am Ceram Soc 101(10):4486-4491

[16] Wei XF, Liu JX, Li F, Qin Y, Liang YC, Zhang GJ (2019) High entropy carbide ceramics from different starting materials. J Eur Ceram Soc 39(10):2989-2994

[17] Harrington TJ, Gild J, Sarker P, Toher C, Rost CM, Dippo OF et al (2019) Phase stability and mechanical properties of novel high entropy transition metal carbides. Acta Mater 166:271-280

[18] Bao W, Wang XG, Ding H, Lu P, Zhu C, Zhang GJ et al (2020) High-entropy M2AlC-MC (M=Ti, Zr, Hf, Nb, Ta) composite: synthesis and microstructures. Scripta Mater 183:33-38

[19] Feng L, Fahrenholtz WG, Hilmas GE, Zhou Y (2019) Synthesis of single-phase high-entropy carbide powders. Scripta Mater 162:90-93

[20] Ye B, Wen T, Huang K, Wang C-Z, Chu Y (2019) Firstprinciples study, fabrication, and characterization of (Hf0.2Zr0.2Ta0.2Nb0.2Ti0.2)C high-entropy ceramic. J Am Ceram Soc 102(7):4344-4352

[21] Shetty DK, Wright IG, Mincer PN, Clauer AH (1985) Indentation fracture of WC-Co cermets. J Mater Sci 20:1873-1882. https://doi.org/10.1007/BF00555296

[22] Liu JX, Kan YM, Zhang GJ (2010) Synthesis of ultra-fine hafnium carbide powder and its pressureless sintering. J Am Ceram Soc 93(4):980-986

[23] Feng L, Fahrenholtz WG, Hilmas GE (2019) Low-temperature sintering of single-phase, high-entropy carbide ceramics. J Am Ceram Soc 102(12):7217-7224

[24] Shannon RD (1976) Revised effective ionic radii and systematic studies of interatomic distances in halides and chalcogenides. ActaCryst A 32(5):751-767

[25] Chicardi E, García-Garrido C, Gotor FJ (2019) Low temperature synthesis of an equiatomic (TiZrHfVNb)C5 high entropy carbide by a mechanically-induced carbon diffusion route. Ceram Int 45(17):21858-21863

[26] Suetin DV, Shein IR, Ivanovskii AL (2008) Elastic and electronic properties of hexagonal and cubic polymorphs of tungsten monocarbide WC and mononitride WN from firstprinciples calculations. Phys Stat Sol (b) 245(8):1590-1597

[27] Schatt W, Wieters K-P, Kieback B (2006) PulvermetallurgieTechnologien und Werkstoffe. Springer, Berlin, p 507

[28] Pötschke J, Dahal M, Vornberger A, Herrmann M, Michaelis A (2021) Production and properties of high entropy carbide based hardmetals. Metals 11:271

Publisher's Note Springer Nature remains neutral with regard to jurisdictional claims in published maps and institutional affiliations. 